\title{
EL PROCESAMIENTO CULTURAL DEL CUERPO EN MUJERES JÓVENES DE LOS SECTORES MEDIOS DE LA CIUDAD DE BUENOS AIRES
}

\begin{abstract}
EUGENIA ZICAVO*
RESUMEN

El artículo se centra en los códigos culturales que intervienen en la construcción de los modelos de belleza femenina en la actualidad y cómo estos inciden en los comportamientos de las jóvenes de clase media que habitan en la Ciudad de Buenos Aires. Entre los temas principales indagamos en qué medida las jóvenes se sienten interpeladas por los modelos estéticos difundidos por los medios de comunicación y qué grado de influencia ejercen en la configuración y producción social de los cuerpos y subjetividades juveniles.
\end{abstract}

PALABRAS CLAVE: JUVENTUD, MUJERES, CORPORALIDADES

* Argentina, Doctora en Ciencias Sociales, Universidad de Buenos Aires (UBA). Socióloga (UBA), docente e investigadora en la Facultad de Ciencias Sociales (UBA, Instituto Gino Germani), becaria postdoctoral CONICET. E-Mail: eugeniazicavo@yahoo.com. 


\title{
PROCESSAMENTO CULTURAL DO CORPO EM MULHERES JOVENS DE SETORES MÉDIOS DA CIDADE DE BUENOS AIRES
}

\begin{abstract}
RESUMO
O artigo trata dos códigos culturais envolvidos na construção de modelos de beleza feminina na atualidade e como estes afetam o comportamento das jovens de classe média da cidade de Buenos Aires. Entre os principais tópicos, indagamos em que medida as jovens se sentem desafiadas pelos modelos estéticos difundidos pelos meios de comunicação e que grau de influência estes exercem na configuração e produção social dos corpos e subjetividades juvenis.
\end{abstract}

PALAVRAS CHAVE: JUVENTUDE, MULHERES, CORPORALIDADES

\section{THE CULTURAL PROCESSING OF THE BODY IN YOUNG WOMEN OF THE AVERAGE SECTORS OF THE CITY OF BUENOS AIRES}

\begin{abstract}
The article focuses on the cultural codes involved in the construction of models of female beauty in today and how these affect the behavior of middleclass youth living in the City of Buenos Aires. Between the principal topics we investigate in what measure the young women feel addressed by the aesthetic models spread by the mass media and what degree of influence they practice in the configuration and social production of the bodies and juvenile subjectivities.
\end{abstract}

KEY WORDS: YOUTH, WOMEN, CORPORALITIES 


\section{INTRODUCCIÓN}

CADA GENERACIÓN TIENE sus propios modos de procesar distintos aspectos de lo social, entre ellos, los modelos estéticos considerados dominantes dentro de su tiempo y sector social. En el presente artículo nos proponemos indagar de qué manera los modelos de belleza popularizados por los medios de comunicación masiva en la actualidad inciden en las representaciones vinculadas al cuerpo y en los comportamientos, expectativas, hábitos y costumbres de las mujeres jóvenes pertenecientes a los sectores medios de la ciudad de Buenos Aires.

A fin de comprender la estructura de significación vinculada a la estética y la presentación corporal en la que se desenvuelven las jóvenes, nos focalizaremos en sus universos de acción simbólica; es decir, en sus sistemas de interacción, en los que las acciones y discursos cobran sentido para ellas. Existen diversas mediaciones sociales que intervienen en la producción de las corporalidades: los mensajes transmitidos por los medios de comunicación, el tipo de alimentación, el sector social de pertenencia, las condiciones de trabajo, la generación y el género suponen mediaciones sociales que moldean y producen a las diferentes corporalidades. Las jóvenes incorporan estructuras de clasificación — que son siempre de calificación (Bourdieu, 2000) que comparten ciertos rasgos con las de las generaciones precedentes, pero que a su vez tienen características distintivas propias: el cuerpo se asienta en la cultura y las maneras en que es tratado y significado expresan formas de apreciación, preconceptos y sentidos históricamente construidos.

En materia metodológica, optamos por un abordaje de tipo cualitativo, por considerarlo el más adecuado para la índole de este trabajo $\mathrm{y}$, en particular, para el estudio de los discursos y las prácticas de los actores. En este caso, analizamos treinta entrevistas en profundidad realizadas a mujeres heterosexuales de entre trece y diecinueve años, pertenecientes a los sectores medios que habitan en la Ciudad de Buenos Aires. La selección de las entrevistadas se realizó mediante el «método de bola de nieve», con entrevistas abiertas y semiestructuradas, a partir de un cuestionario guía. Cabe aclarar que si bien las técnicas cualitativas de investigación empleadas no pretenden alcanzar generalizaciones explicativas, sus conclusiones apuntan a ser significativas; es decir, pertinentes para dar cuenta de cierto haz de relaciones en un sistema social (Ellen, 1984). Los hechos, las prácticas, las verbalizaciones, nos interesan también según su forma de integración 
en un sistema de significados y de relaciones sociales. Por eso en este tipo de investigación centrada en la dimensión cultural de los fenómenos sociales - en que tratamos de desentrañar los códigos particulares que influyen en las representaciones y prácticas de las jóvenes- el criterio de significatividad resulta fundamental para la selección de discursos, personas, prácticas que observar y registrar, y para su ulterior incorporación al análisis y la construcción de esa lógica en su diversidad (Guber, 1991). Nos interesa problematizar la resistencia o la aceptación - y sus matices - a los modelos estéticos dominantes por parte de las jóvenes, lo cual implica también poner en perspectiva que las estrategias de embellecimiento disponibles en el mercado afirman la relación entre «clase social y el tipo de imagen corporal que opera» (Roca, 2003). En este sentido, el impacto de los modelos estéticos circulantes varía entre las jóvenes de los sectores medios y las pertenecientes a los sectores populares. Si bien las mujeres de ambos sectores están expuestas a los mismos modelos corporales considerados legítimos, el imperativo de su reproducción es bastante más lábil en los sectores populares, en parte por falta de acceso al capital económico necesario que les permita una modelación del cuerpo en tanto bien simbólico (Zicavo, 2011). La técnica cualitativa de entrevista en profundidad, en tanto relación social a través de la cual se obtienen enunciados y verbalizaciones, nos permitió una aproximación al universo de significaciones relacionadas con el cuerpo, la alimentación, los paradigmas estéticos dominantes y las prácticas juveniles vinculadas a ellos.

\section{UN NUEVO MODELO DE BELLEZA}

La comodidad o incomodidad — de movimientos, de exposición, de «naturalidad», de elección de vestimenta, etcétera-, están directamente ligadas a la percepción que las mujeres tienen de su propio cuerpo y el grado de aceptación o rechazo que experimentan hacia el mismo, lo cual impacta en sus modos de presentarse públicamente y en su relación con los otros, ineludibles testigos de su corporalidad (entre las jóvenes, sus «testigos» por excelencia son sus pares generacionales).

Esta mirada se encuentra históricamente condicionada pues las tramas de significación, las categorías de percepción y de apreciación son dinámicas y cambian de generación en generación. La obsesión por la figura encuentra en las nuevas generaciones de jóvenes un nivel hasta el momento desconocido. No porque las modas y los modelos 
estéticos no hayan sido en buena parte de la historia tan arbitrarios como estrictos sino porque hasta el momento ninguno exigía como el actual tamaña disminución del talle femenino. Ello supone un nuevo consenso con respecto a los parámetros de belleza valorados por las generaciones anteriores, ya que se basa en un rasgo sumamente restrictivo: para que los cuerpos femeninos hoy sean considerados bellos, se les ha demandando, cada vez, un menor peso.

Para las mujeres - y en especial para las más jóvenes - el hambre se convirtió en un signo de distinción: tener hambre y «aguantarse», «bancársela», fue resignificado como un rasgo positivo, en tanto opera en favor de un resultado estético valorado. En suma, un sufrimiento que «vale la pena pagar»; una suerte de inmolación de la carne, que como tal es voluntaria, y redunda en una supuesta «salvación»: la de la aceptación. La analogía religiosa no resulta del todo azarosa ya que encuentra su émulo en el ayuno como práctica de autosuplicio, con el fin de expiar lo que socialmente aparece como el peor de los «pecados» contemporáneos: la gordura.

En los últimos años, el bombardeo de imágenes en la televisión, revistas, blogs y redes sociales ha desempeñado un rol fundamental en la transmisión e imposición de modelos de belleza asociados a la delgadez y a la juventud. El punto de referencia y el grado de aceptación, también vinculado a la autoestima, varía de acuerdo a cada mujer pero siempre está atravesado por los parámetros sociales que han sido internalizados: se trata de la mirada propia que ha incorporado la mirada social, «[...] un poder social que debe en parte su eficacia al hecho de que encuentra en aquel al que se dirige el reconocimiento de categorías de percepción y de apreciación que él le confiere» (Bourdieu, 1986).

¿Qué tipo de modelo femenino fomentan los medios? La mujer privada de obtener ese placer sensual que desde siempre albergó el acto de comer, bajo el convencimiento de que lo que verdaderamente resulta seductor no es entregarse a los placeres sino pasar de ellos, restringirlos, volverse una asceta del gusto, cercenar ese sentido, olvidarlo, en pos de la vista y el tacto. Con tal de palpar vientres chatos, con tal de ver avanzar dos palitos como piernas. Cerrar la boca, y punto.

En la denominada «sociedad del espectáculo» (Debord, 1999), el cuerpo asume un valor fundamental en tanto imagen visible del sujeto; las señales emanadas por la exterioridad del cuerpo adquieren así un lugar central a la hora de indicar quiénes somos, reduciéndose muchas veces la identidad del individuo a su presencia, a su cuerpo (Sibilia, 2008). Como consecuencia, la presentación física vale socialmente 
como una presentación moral y la puesta en escena de la apariencia expone al actor a la mirada evaluativa del otro (Le Breton, 2002). La belleza ligada a la menor cantidad de masa corporal se fue instalando al tiempo que se demanda, para esos cuerpos flacos, falsas voluptuosidades (colas paradas, bustos prominentes que solo se consiguen con el auxilio del bisturí y del dinero para costear las intervenciones quirúrgicas, según el caso. Un ideal estético cada vez más alejado de las corporalidades reales, cada vez menos accesible, y quizás, por eso mismo, cada vez más deseado.

\section{LOS «CUERPOS MODELO » Y SU IMPACTO EN LAS JÓVENES}

Nuestro interés se centra en los códigos culturales que intervienen en la construcción de los modelos de belleza femenina en la actualidad y cómo estos inciden en los comportamientos de las jóvenes de clase media que habitan en la Ciudad de Buenos Aires. ¿En qué medida se sienten interpeladas por los modelos estéticos considerados legítimos y difundidos por los medios de comunicación? ¿Qué grado de influencia ejercen en la configuración y producción social de los cuerpos juveniles? ¿Cuál es su impacto en sus estrategias cotidianas, sus hábitos y costumbres? Si bien en las entrevistas las jóvenes dan cuenta de una lectura reflexiva de los cuerpos difundidos por los medios, a los cuales critican por su carácter artificial, al mismo tiempo se trata de un modelo admirado y buscado, al cual intentan adaptarse según sus posibilidades. Una cosa no excluye a la otra. Esta crítica a los «cuerpos mediáticos» puede analizarse desde dos puntos de vista. Por un lado, los consideran cuerpos «perfectos», lo cual habla de la aceptación naturalizada por parte de las jóvenes de un modelo de corporalidad femenina sumamente restrictivo, pero incorporado como paradigma estético, afianzado en sus gustos y parámetros de valoración. Y por el otro, resaltan como un rasgo negativo que su «perfección» sea «artificial», resultado de múltiples intervenciones, desde las meramente cosméticas hasta las que implican cirugías estéticas. Las jóvenes se encuentran en una tensión constante: internalizan como deseables las imágenes corporales transmitidas por los medios de comunicación, sintiendo interés y gusto por las formas que les presentan, pero con la convicción de que esos cuerpos son una construcción si no imposible, al menos muy difícil de alcanzar. Dependiendo de cada cuerpo, la intención y voluntad de adelgazar también revela límites e imposibilidades, y entonces la crítica no pasa por el modelo estético propuesto 
en sí, sino por los esfuerzos que implica intentar parecerse a ellos. En este sentido, la recepción activa que las jóvenes realizan de los mensajes y modelos transmitidos por los medios les permite cuestionarlos, remarcando lo poco saludable e invasivo de determinados parámetros de belleza. Sin embargo, vuelven a ser constantemente bombardeadas por ese «deber ser» idealizado que en definitiva, y a pesar de su posición reflexiva, las interpela.

En la actualidad, el paradigma estético hegemónico prescripto para las corporalidades femeninas encuentra su cristalización más brutal en un sinnúmero de programas televisivos. En relación a las corporalidades consideradas legítimas difundidas por los medios de comunicación, las entrevistadas identificaron a la delgadez cada vez más extrema como condición para aparecer en la televisión, ya sea en programas informativos, infantiles, culturales y especialmente de entretenimientos, en los cuales los cuerpos femeninos son expuestos mediante una presentación crecientemente sexualizada; es decir, la mujer reducida a ser un mero cuerpo-objeto. Por otra parte, señalaron diversos programas que muestran los estilos de vida asociados a la obtención de un «cuerpo mediático», especialmente en las señales de televisión por cable con llegada a los países de Latinoamérica, de gran acceso entre los sectores medios de la Ciudad de Buenos Aires. Entre los mencionados por las entrevistadas cabe mencionar ciertos programas estadounidenses como Bridalplasty, una competencia en la que varias mujeres que ya tienen fijada su fecha de casamiento se enfrentan para lograr la mayor cantidad de cirugías plásticas como premio antes de su boda; o Dr. 90210, un reality que muestra la vida de un cirujano de Beverly Hills en el cual las pacientes son filmadas antes, durante y después de las cirugías estéticas a las que se someten y en las que, invariablemente, declaran que desean operarse para conseguir pareja, trabajo e invariablemente para «levantar su autoestima», con la ilusión de que tener un cuerpo que se acerque a las formas difundidas como legítimas, hará de ellas personas más exitosas en todos los ámbitos de su vida. Si en un comienzo en ese tipo de programas los postoperatorios (dolorosos, llenos de cortes y hematomas) no se mostraban, actualmente también son capturados por las cámaras: ya no se ocultan. Su exhibición (siempre morbosa, siempre obscena) naturaliza ese período del postoperatorio como «precio a pagar» ya no solamente en dinero sino también en dolor y sufrimiento, todo con el fin de «verse bien». Una suerte de tortura consentida y televisada en nombre de la nueva «belleza» que las jóvenes vienen internalizando como modelo. 
Cánulas, mascarillas de oxígeno, agujas, bisturíes, pinzas, todo a la vista. Tanto lo que se agrega (implantes, inyecciones de grasa) como lo que, en tanto obstáculo a la forma deseada, es tratado como mero sobrante: grasa, cartílago, carne. Entretanto el cirujano va explicando el procedimiento a cámara con la tranquilidad de su voz ensayada y una sonrisa que sugiere asepsia, mientras la pantalla se inunda de sangre, de ruidos de aparatos succionando, de sierras, de golpes, de costuras, de movimientos bruscos. Mientras tanto, las celebridades confiesan con creciente orgullo haberse hecho «retoques», y hasta están las que se declaran adictas a las cirugías. Lo que antes se escondía, hoy se promueve. Lo que en las generaciones anteriores se escondía, hoy se exhibe como un signo de estatus.

\section{CUERPO BELlo, ¿CUERPo SALUdABLe? LAS PATOLOGÍAS ALIMENTARIAS}

Los modelos estéticos dominantes ejercen un fuerte impacto en la subjetividad de las jóvenes a edades cada vez más tempranas, en ocasiones, desde la niñez. Dichas conductas y apreciaciones pasan a formar parte - en términos de Bourdieu — de su habitus; es decir, de sus disposiciones duraderas. Actualmente las adolescentes se socializan en un entorno cultural más permisivo en relación a la sexualidad, que les permite presentarse legítimamente como sujetos deseantes -que además, gracias al avance en materia de anticonceptivos y la aparición de la llamada «pastilla del día después» puso al alcance de los sectores medios una efectiva disociación entre sexualidad y reproducción-, pero sus cuerpos, ahora liberados, encuentran en la exigencia estética una nueva cárcel. Mientras se proclama una supuesta liberación de los cuerpos y de las fuentes de placer, hay que restringir la silueta para que logre inscribirse dentro de los códigos culturales valorados. Las mujeres se socializan incorporando dichos modelos como «naturales» y tienden a aceptarlos como ahistóricos, asumiendo valoraciones estéticas que las descalifican y que presentan a uno de los modelos (entre tantos otros posibles) como la única imagen bella posible - que excluye a cualquier atisbo de gordura del canon, aunque solo se trate de un mínimo pliegue - y que agota las opciones de belleza dignas de ser valoradas como tales.

Las medidas de lo bello han sido desde siempre una construcción social arbitraria: los talles, pesos y proporciones considerados ideales han ido cambiando según las épocas y las culturas. Sin embargo en la 
actualidad, una época caracterizada por un creciente culto al cuerpo, las mujeres son interpeladas por mensajes que contienen una fuerte carga de violencia simbólica en la difusión de un modelo corporal legítimo cada vez más restrictivo y que tiene a la delgadez, cada vez más extrema, como requisito. La belleza y el peso «justo», se convierten en variables indisociables (Vigarello, 2005). Con dietas y ejercicios hay que reducir la figura, llevarla a su mínima expresión. Ser flaca pasa a ser decisivo. El objetivo es uno y es claro: adelgazar. La generación de las madres de las jóvenes entrevistadas también ha sido interpelada - aunque en menor medida - por estos mensajes. Pero solo a modo de ejemplo, en apenas treinta años la figura ideal femenina fue perdiendo tantos kilos que quienes fueron consideradas íconos sexis en la década de los 80 en la Argentina hoy no tendrían lugar en las revistas por estar «excedidas de peso». Su espesor, antes deseado, hoy sería su estigma. Por supuesto, que el talle haya adelgazado también tiene su correlato en la aparición de una serie de enfermedades vinculadas a desórdenes alimentarios como la bulimia o la anorexia. Síntomas de los efectos concretos que provoca en el cuerpo la mirada social incorporada como propia. Las consecuencias de la incorporación y naturalización de dichos parámetros estéticos también involucran conductas alimenticias muchas veces rayanas con la enfermedad.

Entre las jóvenes entrevistadas, los desórdenes alimentarios son moneda corriente, aunque con diversos grados de peligrosidad: desde las que se someten a dietas estrictas sin supervisión médica hasta quienes se obsesionan al punto de desarrollar enfermedades como la bulimia o la anorexia, que muchas jóvenes ya no consideran patologías peligrosas sino una suerte de estandarte e incluso en algunos casos un signo valorado y reivindicado como parte constitutiva de la identidad buscada. En general, no existe una preocupación por el bienestar físico integral sino exclusivamente por el aspecto: sus cuerpos son jóvenes y sanos y las adolescentes están dispuestas a incluso «enfermarlos un poco» con tal de verse bien. Ciertas jóvenes se reivindican como discípulas de «Ana y Mía» - las nuevas diosas juveniles antes conocidas como anorexia y bulimia - que desde la web detallan las horas que estuvieron sin comer y enumeran la cantidad de vómitos y kilos perdidos para acercarse a un ideal cada vez más restrictivo. De hecho existe una gran cantidad de sitios web en Argentina administrados por adolescentes que se declaran explícitamente «a favor de los desórdenes alimenticios» y que consideran a la anorexia, la bulimia y la automutilación (entre otros) como «estilos de vida» y no como enfermedades a ser 
tratadas. Entre algunos de sus lemas está «Vivir para morir delgada» y reivindican el derecho de intervenir sobre sus propios cuerpos privándose de comer, aún con el riesgo de llegar al extremo de hacerlos desaparecer. Si bien ninguna de las entrevistadas declaró tener un blog de dichas características, muchas visitan asiduamente ese tipo de páginas y en ocasiones suman sus comentarios, movilizadas por la empatía que les generan las experiencias allí narradas. Están las que se muestran sumamente críticas, pero también las que naturalizaron la existencia de dichos discursos como parte de una subcultura juvenil aceptada y en algunos casos, hasta admirada. Los resultados estéticos que algunas jóvenes suben a esos sitios hoy son retroalimentados por plataformas como Facebook - aunque debido a sus contenidos y a la política interna de dicha red social, este tipo de páginas suelen ser dadas de baja - donde también hay páginas como «Yo también fui amiga de Ana y Mía» o «Unidos contra las princesas de Ana y Mía». Lo cierto es que alrededor del fenómeno se ha desarrollado toda una subcultura juvenil con sus íconos (hadas, alas, coronitas) y tatuajes que ocultan cicatrices autoprovocadas o en algunos casos, las destacan. Las jóvenes las conocen, están familiarizadas con dicho universo. Asimismo en las entrevistas mencionaron diversos referentes como el libro «Abzurdah» de Cielo Latini publicado originalmente en 2006 y que surgió de su blog llamado «Me como a mí» en el que narraba sus experiencias en relación a la bulimia y la anorexia y alentaba a otras chicas a dejar de comer para alcanzar la «perfección», libro que continúa cosechando reediciones y se convirtió en un exitoso fenómeno editorial tanto en Argentina como en Latinoamérica, que hizo de su autora una verdadera celebridad literaria entre las más jóvenes. Allí, entre otras cosas, se describía como «insuficientemente flaca para llamar la atención». También fue mencionada a la cantante Florencia Villagra, que en 2004 fue finalista del certamen musical televisivo Operación Triunfo, un reality que obtuvo récords de audiencia en Argentina, autora de la canción «90-60-90» conocida por las jóvenes, cuya letra tiene pasajes como: «Comprendo que le temas al espejo/ lo miro de reojo igual que vos/ Que esto no es lo suficientemente firme y curvo/ Y esto aún no está del todo plano»o «Entiendo que te sientas aturdida /A veces me confundo como vos/El último bocado activa, la culpa que traes escondida/ Y si ese chocolate te venció/ Tal vez deba salir por donde entró». Y también blogs y diversos soportes en internet en los que miles de adolescentes reflejan sus inquietudes, intercambian consejos y escriben mensajes de aliento para seguir adelgazando, pero deseando 
íntimamente que fracasen, porque si son muchas las que logran alcanzar el ideal, el mismo deja de tener peso - más allá del oxímoron que en este caso implique la analogía - Si todas son flaquísimas, si finalmente todas lo consiguen, no hay de quien diferenciarse, el fantasma de «la gorda» se diluye, abandona su referente, pierde sentido. Solo se puede ser flaco o gordo en relación a otro, se trata de un estado relacional, que funciona «en comparación a». En este sentido, en su historización sobre el concepto de «gordura» en Occidente, George Vigarello menciona que durante siglos ninguna medida daba el umbral de lo que era ser considerado «gordo» - fuera de la dificultad para moverse a causa del peso - y que incluso la antigua «gordura» podía ser valorizada como signo de abundancia, de riqueza, de distinción e incluso de autoridad, siempre y cuando no se opusiera a la movilidad (Vigarello, 2011).

En la actualidad, desde la prensa se instalan nuevos conceptos como el thigh gap (el espacio que, como muestra de delgadez, se supone debe quedar entre las piernas) que se ha convertido en el nuevo blanco de una mirada cada vez más excesivamente particularizada. Las jóvenes suben fotos de sus piernas separadas como muestra de su belleza alcanzada, asociada a la delgadez: sus muslos sin rostro y con poca carne que se vuelven un signo de distinción entre sus pares. Hace poco en Estados Unidos surgió el término thinspirations, un significante bastante inequívoco: mujeres que son «modelos de inspiración» para sus congéneres no por tener determinado saber, talento o destreza, sino por ser muy flacas. Mientras tanto, las entrevistadas expresan la angustia que experimentan al salir a comprar ropa debido a que no siempre encuentran talles acordes a su cuerpo, o no se sienten «favorecidas» por lo que está de moda, y en la mayoría de los casos bajar de peso está entre sus objetivos vitales a corto plazo:

A mí me cambiaron la vida unas pastillas que empecé a tomar por recomendación de una amiga. No tienen anfetaminas ni nada y me las da un doctor, son naturales, pero te sacan un poco las ganas de comer y eso ayuda. Por suerte ya bajé un par de kilos. A veces te marean un poco o te dan diarrea, pero está todo bien. Eso sí, a mi mamá no le dije nada, porque si se entera de que estoy tomando pastillas, me mata (Laura, 17 años).

Yo soy la única de mi división que oficialmente tuvo anorexia el año pasado y tuve que hacer tratamientos y todo. Pero hay otras amigas que están mucho peor que yo y nadie les dice nada. Y la verdad que yo tam- 
poco había logrado estar flaquísima, solo bajé algunos kilos, pero es cierto que me había obsesionado, que cada vez comía menos. El tema es que aunque te digan que según tu altura y tu masa corporal y no sé qué otras cosas te miden, te dicen que estás bien, si el pantalón no te entra, no te entra y chau, listo. Todo bien con ser sana, pero yo quiero que me entre el pantalón. Igual ahora estoy menos loca con el tema, pero me cuido en las comidas, no como dulces, trato de al menos mantenerme (Julieta, 15 años).

No creo que vomitar de vez en cuando te convierta en bulímica o anoréxica, es algo que podés hacer si ves que te pasaste o si te sentís muy pesada, no es algo lindo así que tampoco vas a estar vomitando lo que comés todos los días, pero yo lo hago de vez en cuando y no veo que sea un problema (María, 14 años).

En los desórdenes alimentarios intervienen un sinnúmero de factores: los mensajes e imágenes difundidas por los medios, el propio entorno en el cual se socializan las niñas y adolescentes, pero también el modelo que se consume y reproduce al interior de la familia, institución socializadora por excelencia. Las jóvenes comparten determinados códigos - entre los que prima cierto consenso tácito de que es preferible dejar de sentirse bien físicamente en favor de sentirse bien estéticamente - y a su vez son educadas por mujeres que, socializadas con otros modelos corporales, hoy también son interpeladas por los códigos estéticos de sus hijas. Las entrevistadas mencionan que sus madres se someten a dietas, tratamientos, cremas, inyecciones de bótox o intervenciones quirúrgicas y que, aunque en general están más ligadas a enmascarar el paso del tiempo, también tienen a la delgadez como referente:

Mi mamá pasó por una etapa de gordura después de los embarazos de mis hermanos y como yo soy la única hija mujer, como que se obsesionó conmigo, en algún punto lo hace por mi bien, porque no quiere que sea gorda y que la pase mal, porque a nadie le gusta ser «la gorda del curso» (Elena, 14 años).

Desde chica yo sé qué engorda y qué no. Tampoco es tan difícil, en mi casa siempre se comieron cosas light. Cuando aparece una amiga y te pregunta si un pancho engorda es obvio que sí, está el pan, las grasas, todo, si querés adelgazar mejor comete una manzana. Eso lo sabemos todos (Georgina, 17 años). 
En relación al vínculo establecen con sus madres en relación a la comida, el mismo aparece como un espacio de conflicto, ya sea porque las jóvenes se niegan a comer determinados alimentos o porque sus madres insisten en que dejen de comerlos. En este sentido, y volviendo a la difusión mediática de modelos corporales que a su vez prescriben modos de conducta, llaman la atención algunos de los programas de televisión mencionados por las entrevistadas como «Toddlers \& Tiaras», traducido en Latinoamérica como «Princesitas», un reality show estadounidense que se emite desde 2009 en el que niñas de a partir de dos años de edad, compiten en concursos de belleza alentadas (y preparadas) por sus propias madres. Mujeres que instan a sus hijas a que no coman ni un chocolate antes de mostrarse en la pasarela, ante los recurrentes - y más que justificados - pataleos de las pequeñas.

Quizá el ejemplo más paradigmático en este sentido sean los estrenos de 2013 de la señal «Discovery Home \& Health» canal de cable a la que acceden la mayoría de las jóvenes entrevistadas, en el que conviven los siguientes programas «Niños pizzas y papas fritas», «Programados para engordar» y «Mi mamá me tiene a dieta», el más emblemático para analizar este fenómeno por ser el más mencionado entre las entrevistadas y porque atraviesa generaciones y tiene un especial impacto en las niñas y adolescentes. En dicho programa, en registro documental, se muestra a tres madres que, obsesionadas con contar calorías, someten a sus hijas a rutinas de ejercicio físico y dietas estrictas, influyendo en su percepción sobre la imagen corporal y la comida. Niñas que a los cinco años se miran al espejo, serias, y le dicen a su madre «estoy gorda». Madres que les recitan a sus hijas, con tono de sargento, una larga lista de alimentos totalmente prohibidos en su dieta.

Como vimos, la «belleza» es un significante que puede albergar distintos significados. Los rasgos que para cada cultura y período histórico significan lo bello son arbitrarios, resultados de luchas por la imposición de sentidos en diferentes esferas como la salud, la industria de la moda, la publicidad, los hábitos alimentarios y el lugar que ocupan las mujeres en la sociedad. Ninguno de estos aspectos es ajeno al modo en que las adolescentes se plantan ante el mundo en relación a su presentación corporal. Un mundo que empieza por el espejo en el que se buscan en el baño de la casa familiar o detrás de la puerta del clóset, el reflejo a través del cual buscan construir su identidad mientras su cuerpo crece, se desarrolla, se expande, muta. Y en algún momento, se detiene, para. Y es cuando hay que «modelar» la calma. Esa 
que, dicen, precede a toda tormenta. Porque lo que viene después, en la mayoría de los casos, es la tormenta (y el tormento) de la disconformidad con las formas y las medidas del cuerpo propio, con esa delimitación física que hasta entonces no había merecido demasiada atención y que, de repente, se torna central. Para la mirada de los varones pero sobre todo del grupo de amigas. Y también para los miembros de la familia, cuya cercanía los habilita a opinar y emitir juicios sobre tal o cual apariencia. «Estás más flaca», ya sea como afirmación o interrogante, se ha convertido en el elogio por antonomasia. «iEngordaste?», la pregunta prohibida.

A los diez (años) empecé a fijarme más en el cuerpo, mi papá me decía estás subiendo de peso, no comas tanto (Chiara, 13 años).

Si te digo qué quiero cambiar de mi cuerpo te digo todo. Bah, todo no, pero odio mis piernas, son muy gordas sobre todo arriba que se me juntan, por eso no me pongo minis. Y después la parte de la cola, que vestida capaz que no se nota pero tengo celulitis mal. El otro día me vio mi mamá y no podía creer que tuviera tantos pozos a mi edad. Supongo que cuando sea más grande algo voy a hacer, un quirófano, algo. ¡Y de paso me hago las lolas! (Mariana, 19 años).

Los temores que provocan el sobrepeso y la obesidad en miles de personas - en particular en las mujeres - han hecho que muchas madres se obsesionen con el tema de la alimentación de sus hijas y se conviertan en verdaderas tiranas cuando de la comida se trata. Algunos síntomas propios de la época: madres instruyendo a sus hijas no en la comida sana - paradigma de la maternidad responsable durante décadas - sino de lo que no engorda; niñas y adolescentes expertas en cantidad de calorías, en regímenes alimentarios, en balanzas y visitas a nutricionistas. Bajar de peso: esa es la fantasía que albergan aquellas que no alcanzaron el objetivo que se fijaron pero también es la experiencia de las que «lo lograron», quienes hicieron dicha transición estética — sin necesariamente padecer anorexia o bulimia- y cuya obsesión radica en nunca más volver a subir de peso. El estigma de la gordura es su peor fantasma.

Yo me estaba matando por sacarme un diez en todo y al final me di cuenta de que dejar de comer un alfajor en el recreo y empezar a ser «de las flacas» era más fácil que ponerse a estudiar. Lo digo de verdad, me gustó lo que empezó a pasar alrededor mío cuando empecé a hacer dieta 
y a estar más flaca, yo había sido siempre la nerd y aunque nunca había sido gorda era como del montón. Cuando empecé a bajar de peso empecé a tener nuevas amigas, a salir con otros grupos, a pasarla bien. Ni loca quiero volver a engordar (Carolina, 16 años).

A su vez, la juventud es un territorio de colonización para el mercado, con sus ídolos cada vez más tempranamente sexualizados, que aparecen como ideales ante todo estéticos - si actúan, cantan o bailan, parece ser meramente subsidiario de su belleza y su delgadez-. En el caso de las mujeres, la industria de los ídolos juveniles muestra a jóvenes cada vez más sexis, más flacas, con menos ropa y en actitudes más provocativas. Para tener esos cuerpos - que en la pantalla y los escenarios aparecen tan sueltos, tan libres, tan bellos - hay que hacer esfuerzos, claro, pero la seguridad que otorgan - precisamente en momento en el que las mutaciones no solo corporales sino de ideas, gustos, de relación con los padres son constantes-, hace que en la economía libidinal juvenil, valga la pena el esfuerzo. El lugar subjetivo de seguridad por excelencia está dado por la presentación corporal. Un cuerpo controlado, dócil, que logre reducir sus formas: el producto final de un sinfín de prohibiciones. Mientras un aluvión de programas televisivos proponen castings y rondas eliminatorias para elegir «la modelo del año» entre jóvenes hasta entonces ignotas y los medios del mundo hacen circular una entrevista en la que la editora de Vogue la revista que a nivel mundial es sinónimo y referente del mundo de la moda y del paradigma de belleza para las mujeres - confiesa que las modelos comen papel para no engordar, distintos medios reproducen un discurso que insiste con los «verdaderos cuerpos de las mujeres», mientras en sus mismas páginas lo cierto es que hasta los bebés hoy son retocados digitalmente en las fotos publicitarias. Con la ayuda de Photoshop, hasta las ficciones se instalaron como «referentes» para los cuerpos reales: las heroínas del manga japonés (género que pasó de la historieta al mundo de la animación) con piernas del grosor de un brazo flaco, minifaldas mínimas y pechos exagerados extendieron sus dominios simbólicos por fuera del cómic. Las Barbies - durante décadas muñecas de la exageración, pero reinas del terreno de los juegos - encontraron sus émulos en la vida real: jóvenes que, con su mayoría de edad recién estrenada, decidieron voluntariamente someterse a cirugías para adecuar su imagen a un imposible ahora posible: si Barbie era un ícono, ellas quieren encarnarlo, en ocasiones, demasiado literalmente. 


\section{LA EXPOSICIÓN DEL CUERPO EN LAS REDES SOCIALES}

Herederas del fotolog, actualmente las adolescentes se socializan en entornos digitales en los cuales, literalmente, «una imagen vale más que mil palabras». En este sentido, la cultura visual de las redes sociales como Facebook ha hecho de los cuerpos un objeto de exposición constante, en la cual la presentación pública pasa casi exclusivamente por la imagen. Linne y Basile (2013) indagaron en las distintas corporalidades que exhiben a través de Facebook las mujeres adolescentes de la Ciudad de Buenos Aires, un segmento social que ha desarrollado en los últimos años mayores usos y apropiaciones de la fotografía digital, volviéndola una actividad clave de su sociabilidad. Según afirman, las adolescentes, nativas digitales socializadas desde la infancia con los nuevos medios, conforman el sector más numeroso y activo en dichas prácticas: «La adolescencia es el período de construcción identitaria por excelencia, los adolescentes son quienes más utilizan la red social y a su vez quienes más fotos personales publican (Facebookstats.com, 2013). Así, el número de fotos publicadas en Facebook por mujeres adolescentes oscila, en promedio, entre seiscientas y mil. En cambio, en el caso de las preadolescentes entre once y trece años, el número de fotos publicadas tiende a disminuir considerablemente: la mayoría tiene menos de cincuenta fotos publicadas en la plataforma» (Linne y Basile, 2013). En general se trata de fotos posadas con sonrisas y expresiones ensayadas, divertidas o sexis que las jóvenes capturan, editan y publican y que al circular entre su grupo de pares forman una parte fundamental de su autopresentación en internet. Si antes se trataba de «jugar a la modelo» frente al espejo, ahora las redes sociales ofician de reflejo y además permiten medir la aceptación que dicha presentación pública genera, cuantos «me gusta» cosecha.

En sus estudios sobre la presentación personal, Erving Goffman (2001) utiliza la metáfora teatral de la puesta en escena aplicada a la vida cotidiana para analizar cómo los marcos de interacción social van normando los aspectos corporales y de la personalidad que se muestran y aquellos que se ocultan o se intentan ocultar. En esa interacción se presenta la influencia recíproca de cada uno sobre las acciones del otro; hay un actuar para el otro. En este caso, las jóvenes se presentan en escena ante un otro bajo una preocupación constante hacia el propio cuerpo que intenta seducir para captar la mirada de los demás (o al menos no «defraudarla»). Aunque hay jóvenes que realizan retoques digitales en las fotos que suben a la web y a partir de la existen- 
cia de programas como el Photoshop el valor testimonial de una fotografía se volvió cada vez más relativo, también hay algo de la cultura de la inmediatez posibilitada por los teléfonos celulares con cámaras fotográficas y conexión a internet, que dificulta moldear la imagen final por antojo porque capturar el momento y compartirlo al instante, a modo de «primicia», es uno de los usos más valorados dentro de las redes sociales. Por ello, si antes las adolescentes pasaban mucho tiempo frente al espejo, hoy lo pasan frente a la pantalla del celular, que también las refleja, y en la que en general buscan - a partir de la pose - una imagen mejorada de sí mismas.

En este sentido resulta útil retomar la idea propuesta por Gil Calvo (2000) sobre una mujer que se desdobla en dos identidades: por un lado, la mujer interna que se ve a sí misma (la propia imagen privada) y por otro, la mujer externa que es vista por otros (la imagen pública). Sin embargo, para que pueda tomarse en consideración la impresión que con el propio aspecto se causa, resulta necesario que antes se haya interiorizado la existencia del otro generalizado (Mead, 1968); es decir, lo que el propio cuerpo provoca a todos en general y a nadie en particular: ¿qué piensan de mí aquellos que no me conocen?, ¿cómo me ven?, ¿qué pueden decir acerca de mí a partir de mi apariencia? Los otros son muchas veces pensados como jueces externos de la propia apariencia, aunque en rigor es el propio juicio crítico el que se imaginan que emiten.

La mirada del otro cumple un rol central en la percepción de sí mismas que tienen las jóvenes pero, desde su perspectiva, esta mirada no es contemplativa sino más bien evaluativa; los otros son vistos no tanto como «amigos» sino como «enemigos» que juzgan y critican. Presentarse ante los otros supone el deseo de sentirse aceptada, aprobada por otros generalizados y otros significantes. Los otros significantes (familiares cercanos, amistades, parejas, etcétera) pueden ser tomados como referentes para la propia percepción del cuerpo no necesariamente por lo que digan o hagan sino por el modo en que se presentan (y perciben asimismo su apariencia) ante dichas personas. En estos casos, la búsqueda de aceptación deja de ser impersonal y se orienta hacia un otro particularizado que es a su vez una mirada considerada relevante que impactará así en la autopercepción. Este otro particularizado otorga materialidad a la preocupación por el cuerpo; ya no se erige en el vacío sino en pos de ese otro que concretamente mira y evalúa, a quien quieren agradar, seducir. Al afrontar la exigencia social de presentarse de manera atractiva, y al buscar impresionar 
favorablemente a los posibles «admiradores», no solo se persigue la aprobación del otro generalizado sino también de una otra generalizada; es decir, de las potenciales mujeres competidoras que son, en efecto, las verdaderas expertas y mejores críticas en materia de seducción por estar tradicionalmente socializadas para ello. Mientras que el juicio de los varones puede estar sesgado debido a su interés sexual, el de las otras mujeres es un juicio especializado, fundado en su experiencia como «objetos de admiración y deseo». De este modo, las amigas se tornan un punto de referencia importante cuando portan el cuerpo socialmente legitimado ya que son vistas como cuerpos reales que han logrado acercarse al ideal corporal haciendo posible el modelo que aparentaba ser imposible alcanzar. Las jóvenes invierten recursos en su imagen corporal que ha de ser pensada para ser mirada. Es decir, (re)conocen la mirada que recae sobre sus cuerpos y por lo tanto se preparan para ser observadas. De este modo «se refuerza y reproduce el círculo vicioso del arco reflejo estímulo-respuesta» (Gil Calvo, 2000:133). Especialmente en etapas transicionales como la adolescencia en las que hay una construcción activa del «yo» y de su presentación en sociedad, las seguridades no abundan. Hay jóvenes que prefieren no salir si «se les nota la panza» pero también quienes prefieren no ser vistas por sus pares si antes no se plancharon el pelo o no se maquillaron o no tienen las uñas prolijamente pintadas o no tienen alguna prenda de determinada marca. En cualquier caso, su voluntad de intervenir sobre su presentación estética implica una disconformidad con el propio cuerpo tal cual es y por ello hay que de algún modo esconder o «disfrazar», y operan como una suerte de «muletas» para la aceptación. Signos que las adolescentes asocian a una presentación estética valorada, que como contrapartida tiene a la desvalorización como amenaza (en muchos casos ilusoria), en caso de no ser sus legítimas portadoras.

Vivimos en una sociedad de signos, todo el tiempo realizamos operaciones de decodificación de los mismos. Y los jóvenes suelen ser los grupos mas sobresignificados, y por ende mayormente sobrenterpretados. Un pin (prendedor), determinado corte de pelo o una remera con el logo de una banda musical «dicen» por ellos sin que, todavía, hayan tenido que articular palabra. Y en ocasiones, ni siquiera lo hacen. Son señas para reconocer y ser reconocidos por aquellos que comparten o desean compartir su universo de sentidos, sus espacios de encuentro y disfrute, sus consumos. Hay cuerpos cómodos y otros claramente molestos, que ven sus formas cambiar y se debaten entre 
los pliegues de su piel. Especialmente para las mujeres, la adolescencia es un momento de dietas, de consejos en relación a como adelgazar, de amigas que se acompañan a hacer gimnasia o cuentan obsesivamente las calorías de los alimentos que ingieren y también de los alimentos que no. Están pendientes de lo que comen durante los recreos del colegio, saben con precisión milimétrica qué come cada una. La comida es omnipresente, tanto como la revolución hormonal que acompaña al crecimiento con signos tan indeseados como propios de la edad como los granos, los cambios abruptos de estatura, el desarrollo no siempre parejo de las distintas partes de un cuerpo que muta y que en ocasiones parecería ajeno, incontrolable.

\section{REFLEXIONES FINALES}

En relación a la manera de sentirse con respecto a su propio cuerpo, y en la forma en que este sentimiento impacta sobre su subjetividad y emotividad, el binomio delgadez/gordura es un factor que influye de manera determinante en las jóvenes entrevistadas. La seducción, las ganas de agradar y de ser aceptada empieza para las adolescentes por el propio grupo de amigas. Los casos de chicas que adelgazaron significativamente durante su adolescencia dan cuenta de una suerte de «reenclasamiento» estético que es vivido como sumamente positivo por aquellas que, habiendo tenido un cuerpo que no se adecuaba a los modelos de belleza legitimados socialmente, pasaron a ser sus vivas portadoras. La delgadez brinda seguridad de movimientos, libertad para elegir prendas de vestir, en suma, la soltura necesaria para moverse con «naturalidad». En términos de Bourdieu, la delgadez posibilita una determinada hexis corporal que, en una sociedad en la que la imagen cobra cada vez más relevancia, se constituye en un signo de distinción que facilita - cuando no garantiza - la aceptación social. La belleza, empezando por la delgadez, es vista como un facilitador del éxito. En ese sentido, estar flaca abriría las oportunidades en el «mercado de la conquista», tanto de potenciales parejas como de amistades. La cadena de mediaciones y correspondencias mecánicas se construye del siguiente modo: la delgadez se equipararía a ser atractiva y ser atractiva significaría ser merecedora de afecto.

El modo en que las jóvenes entrevistadas perciben a su propio cuerpo tiene un estrecho impacto en el plano emocional - que puede expresarse en la euforia por haber bajado de peso o en la angustia por descubrir que el pantalón ya no cierra- y ocupa un lugar muy impor- 
tante, vinculado a la dinámica relacional que se establece con la mirada evaluativa del otro. Las diferentes emociones experimentadas por las entrevistadas tales como la angustia y la culpa por comer «de más» encuentran una suerte de «consuelo» en la creciente oferta mercantil orientada hacia el «mejoramiento» estético: cremas, gimnasia, pastillas, tratamientos reductores. El ser idealizado implicaría un deber hacer. Encontramos que la creencia en la efectividad de dichas intervenciones influye de manera positiva en su autoestima y seguridad, incluso antes de comprobar los efectos de las mismas. El hecho de que exista la posibilidad, o la promesa, de cambiar aspectos considerados defectuosos, proporciona seguridad y tranquilidad, incluso más que otros atributos identitarios no vinculados con lo estético.

También aparecen discursos relacionados con la culpa después de comer en exceso o tras ingerir alimentos con muchas calorías, pero también con el esfuerzo o sacrificio por no «tentarse» o «comer de más». Las jóvenes no se sienten habilitadas a disfrutar plenamente de esos consumos debido al temor a engordar y así alejarse del modelo de belleza considerado legítimo. Por eso cuando ceden, aparece la culpa. Hay un fantasma que recorre el imaginario femenino: la gordura. Una cultura en la cual la belleza - ligada a la juventud pero también, independientemente de la edad, a la delgadez - aparece como mandato sustentado en la idea de que el individuo es responsable de su propia imagen, presupone que el ideal siempre puede alcanzarse a base de esfuerzo, sacrificio personal o voluntad. Y es así como el fracaso adopta otro sentido, que deviene sentimiento de culpa y hasta de victimización, debido a una «acentuación de normas que, en las sociedades occidentales, fueron dando cada vez más exigencia y precisión a la apariencia corporal y a la expresión de sí mismo» (Vigarello, 2011:11). En consecuencia, el bienestar individual termina viviéndose como una presión.

El modelo de belleza socialmente legitimado aparece una y otra vez en el discurso de las entrevistadas como un modelo ligado - no exclusivamente, pero sí prioritariamente - con la delgadez. En general alcanzar este ideal de belleza es una preocupación compartida por todas. «Gorda» es el peor insulto. El hecho de contar con el modelo de cuerpo establecido socialmente implica poseer recursos que confieren a sus protagonistas cierto poder para controlar estratégicamente su entorno personal.

Uno de los beneficios de la belleza mencionados por las entrevistadas es el hecho de que les permite relacionarse con una mayor cantidad de personas y posibilita una mayor integración en diferentes gru- 
pos, tanto en el mundo virtual como en la interacción cara a cara. La correspondencia con el modelo de belleza hegemónico también otorga determinadas «habilidades» y sobre todo seguridades a la hora de relacionarse con otros. Un cuerpo bello es un cuerpo cómodo, que sabe cómo manejarse con soltura, que está acostumbrado a ser aceptado y por eso se mueve con naturalidad. En la presentación ante los otros, la distancia entre el cuerpo ideal y el cuerpo real (el que cada una posee) adquiere un lugar central ya que la posibilidad de experimentar el cuerpo bajo los signos de la incomodidad, la rigidez o la timidez es mayor cuanto mayor es la desproporción entre esos dos cuerpos (Bourdieu, 1986). El cuerpo que no gusta puede convertirse en una barrera para comunicarse y relacionarse con los otros. «Verse bien» las hace sentir cómodas, libres para expresarse, para mostrarse ante las miradas ajenas. Por el contrario, no tener un cuerpo que se adecue al modelo socialmente legitimado genera un rechazo para consigo mismas que puede reforzarse con sentimientos relacionados con la exclusión, que a su vez resultan en angustia, baja autoestima y problemas a la hora de relacionarse con los otros, hechos también relacionados con trastornos alimenticios como la anorexia y la bulimia, padecidos principalmente por mujeres.

La mayoría de las jóvenes se siente descontenta con su cuerpo y puede enumerar en detalle aquellas partes que quisiera modificar. ¿Por qué tamaña baja de la autoestima colectiva? En parte porque ha habido una transformación del ideal de belleza y el parámetro comparativo, el ideal a alcanzar, pasó a ser más bien una utopía. La propia mirada es implacable: el cuerpo aparece como una suma de particularidades que deben congraciarse con un ideal estético sumamente restrictivo, que tiene como aliadas a las propias mujeres. En el plano emocional, la culpa es el sentimiento más recurrente, así como la fantasía de que un cuerpo más próximo al ideal difundido será la solución para los asuntos más diversos. Independientemente de su peso, todas comparten el mismo presupuesto: que serían más felices si estuvieran más flacas. La delgadez se convirtió no solo en condición indispensable para que un cuerpo sea considerado «bello» sino en un mandato moral: la estética prescribe una ética.

Buenos Aires (ARGENTINA), OCTUBRe 2013

RECIBIDO: OCTUBRE 2013 ACEPTADO: DICIEMBRE 2013 


\section{REFERENCIAS BIBLIOGRÁFICAS}

BOURDIEU, PIERRE (1986): «Notas provisionales sobre la percepción social del cuerpo». En W. MiLls et al.: Materiales de sociología crítica. Madrid: La Piqueta.

(2000): La distinción: criterios y bases sociales del gusto. Madrid: Taurus.

DeBord, GuY (1999): La sociedad del espectáculo. Valencia: Pre-Textos.

EELlEN, RoY (1984): Ethnographic Research. A Guide of General Conduct. London: Academia Press.

Gil CAlVo, ENRIQUe (1992): La mujer cuarteada. Útero, deseo y safo. Barcelona: Anagrama.

_ (2000): Medias miradas. Un análisis cultural de la imagen femenina. Barcelona: Anagrama.

GOFFMAN, ERVING (2001): La presentación de la persona en la vida cotidiana. Buenos Aires: Amorrortu.

Guber, RoSAnA (2001): La etnografía. Método, campo y reflexividad. Buenos Aires: Norma.

LE BRETON, DAVID (2002): La sociología del cuerpo. Buenos Aires: Nueva Visión.

LINNE, JOAQUín y DIEGO BASILE (2013): «Tipos de fotos publicadas en facebook por mujeres adolescentes de la Ciudad de Buenos Aires». Actas de las X Jornadas de Sociología de la UBA. Buenos Aires: Universidad de Buenos Aires.

MEAD, GEORGE (1968): Espíritu, persona y sociedad. Buenos Aires: Paidós.

ROCA, ALEJANDRA (2003). «Cuerpo y medios de comunicación: viejas obsesiones y nuevas tecnologías. El cuerpo en revistas femeninas argentinas». Cuadernos de Antropología Social. Buenos Aires: Facultad de Filosofía y Letras, Universidad de Buenos Aires.

SibILIA, PAUla (2008): La intimidad como espectáculo. Buenos Aires: Fondo de Cultura Económica.

Vigarello, GeORge (2005): Historia de la belleza. El cuerpo y el arte de embellecer desde el Renacimiento hasta nuestros días. Buenos Aires: Nueva Visión.

(2011): Historia de la obesidad. Metamorfosis de la gordura. Buenos Aires: Nueva Visión.

ZiCAVO, EugEnIA (2011): «Modelos corporales de las mujeres: categorías de percepción y sistemas sociales de clasificación». En MARIO MARGULIS, MARCELO URRESTI, HugO LEWIN y otros: Las tramas del presente: desde la perspectiva de la sociología de la cultura. Buenos Aires: Biblos. 